\title{
Prayer-Related Physical Activities for Cardiovascular Health
}

\section{${ }^{1}$ Mahmoud A. Alomari, ${ }^{2} \mathrm{DM}$ Shqair, ${ }^{3} \mathrm{~K}$ Alawneh, ${ }^{4}$ OF Khabour, ${ }^{5} \mathrm{ME}$ Nazzal, ${ }^{5} \mathrm{MA}$ Sadaqah \\ ${ }^{1}$ Department of Physical Education, Qatar University; and Departments of ${ }^{2}$ Nutrition, ${ }^{3}$ Internal Medicine, and ${ }^{4}$ Medical Laboratory, ${ }^{5}$ Rehabilitation Sciences at Jordan University of Science and Technology}

\section{Cardiovascular Health and Physical Activity}

\section{INTRODUCTION}

Cardiovascular (CV) diseases (CVD) are the leading cause of death in the globe, attributed mainly to atherosclerosis (Margetts, 04). Physical activity (PA), on the other hand, is known to modify vascular function and atherosclerosis risk profile (Bouchard, 07).
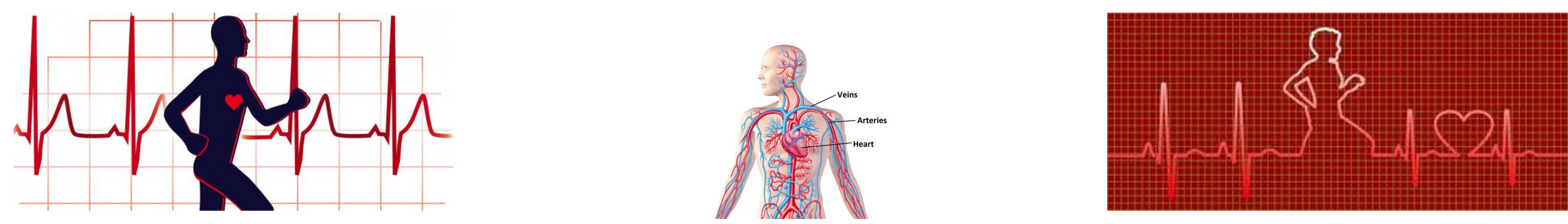

Physical Activity during Muslim Prayer

Muslims pray five times daily, preferably in the Masjid (prayer place). Each prayer is completed in a number of "rakaa". One rakaa: is a set of repetitive physical movements that involves standing, bowing, prostration, and setting. The total daily "rakaa" is 17-30 prayed at dawn (2-4), noon (4-8), late afternoon (4), early evening (3-5), and late evening (4-9), which could take 15-30 mints. Obviously, these physical movements can be considered PAs, especially when walking to the neighborhood Masjid is added.
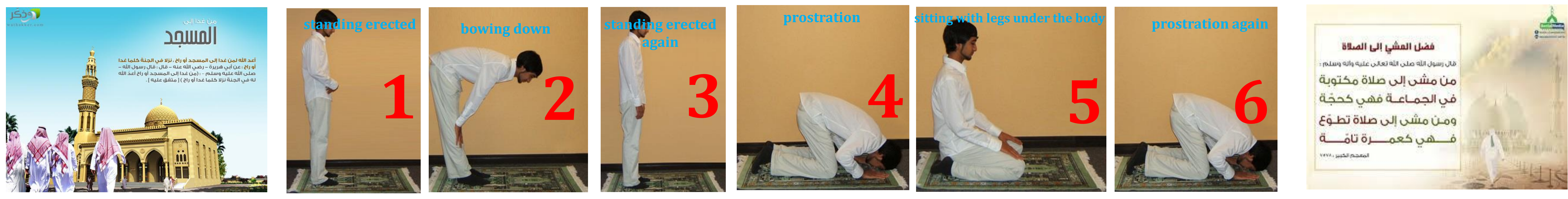

Gaps and purpose

Most studies reported the benefits of recreational and occupational PAs with few examining religious-related PA (RRPA). Therefore, the current study examined the association of vascular function with PAs related to Muslim prayer.

\section{METHODS}

\section{Design and Recruitment}

The study was cross-sectional retrospective to examine the relationship of PA with $\mathrm{CV}$ function in apparently healthy males and females aged $18-80$ years old from the local community. Individuals with diagnoses/risk of CV, metabolic, orthopedic, pulmonary, neurological, and/or psychological diseases were not accepted in the study. Religious-related Physical Activity

Prayer activity data were collected in a 1-to-1 interview. The main outcomes of the prayer activity assessment were daily prayer and rakaa number performed, daily and weekly prayers performed in the Masjid, and time and distance to the Masjid.

Vascular Measurements

Blood flow, vascular resistance, and venous capacitance and outflow at rest and after occlusion were obtained using strain-gauge plethysmography. Immediately before assessments, 2 pneumatic cuffs were placed above the elbow and on the wrist. A strain-gauge, $2-3 \mathrm{~cm}$ less than the forearm circumference, was placed $\sim 10 \mathrm{~cm}$ below th elbow (Alomari, 04).

\section{RESULTS}

\begin{tabular}{lc|}
\hline \multicolumn{2}{l}{ Participant Characteristics $(\mathrm{n}=192)$} \\
\hline Variable & Mean \\
\hline Male/Female & $98 / 94$ \\
Age (years) & $42.67 \pm 19.2$ \\
Height (cm) & $167.32 \pm 1.8$ \\
Weight (kg) & $75.0 \pm 16.53$ \\
Body mass index & $26.8 \pm 5.5$ \\
Waist/Hip ratio & $0.84 \pm 0.11$ \\
Percent body fat & $26.96 \pm 8.5$ \\
\hline
\end{tabular}

\begin{tabular}{|c|c|c|c|c|}
\hline & Blood flow & $\begin{array}{l}\text { Vascular } \\
\text { resistance }\end{array}$ & $\begin{array}{c}\text { Venous } \\
\text { capacitance }\end{array}$ & $\begin{array}{l}\text { Venous } \\
\text { outflow }\end{array}$ \\
\hline aily prayer number & $r=0.1 ; p=0.7$ & $r=-0.1 ; p=0.3$ & $r=0.05 ; p=0.5$ & $r=-0.0 ; p=0.7$ \\
\hline aily raka` number & $r=0.1 ; p=0.3$ & $r=-0.0 ; p=0.5$ & $r=0.1 ; p=0.18$ & $r=0.1 ; p=0.3$ \\
\hline stance to Masjid (m) & $r=0.4 ; p=0.000$ & $r=-0.2 ; p=0.0$ & $r=0.2 ; p=0.03$ & $r=0.2 ; p=0.04$ \\
\hline Time & $r=0.3$ & $r=-0.2 ; p=0.05$ & $r=0.2 ; p=0.02$ & $r=0.2 ; p=0.03$ \\
\hline Neakly prayer in the Masjid & $r=0.2 ; p=0.004$ & $r=-0.2 ; p=0.007$ & $r=0.2 ; p=0.02$ & $r=0.3 ; p=0.001$ \\
\hline aily prayer in the Masjid & $r=0.2 ; p=0.007$ & $r=-0.2 ; p=0.03$ & $r=0.2 ; p=0.03$ & $r=0.2 ; p=0.002$ \\
\hline
\end{tabular}

\begin{tabular}{|c|c|c|c|c|}
\hline \multicolumn{5}{|c|}{ lationship of Prayer Activities with Resting Vascular Function Measures } \\
\hline & Blood flow & $\begin{array}{l}\text { Vascular } \\
\text { resistance }\end{array}$ & $\begin{array}{l}\text { Venous } \\
\text { capacitance }\end{array}$ & $\begin{array}{l}\text { Venous } \\
\text { outtlow }\end{array}$ \\
\hline & & $r=-$ & & \\
\hline & 4 & $=0.9$ & $r=0.1 ; p=0.3$ & $r=0$ \\
\hline ista & $r=0.2$ & $r=-0.0$ & $r=0.1 ; p$ & $r=0.2$ \\
\hline & 2 & $r=-0.05 ; p=0.5$ & $r=0.1 ; p=0.2$ & $r=0.12 ; p=0.1$ \\
\hline & $r=$ & $r=-0.1$ & $r=0.07 ; p=0.3$ & $r=0$ \\
\hline aily prayer in the Masjid & $r=0.1 ; p=0.2$ & $r=-0.1 ; p=0.3$ & $r=0.06 ; p=0.4$ & $r=0.1 ; p=0.05$ \\
\hline
\end{tabular}

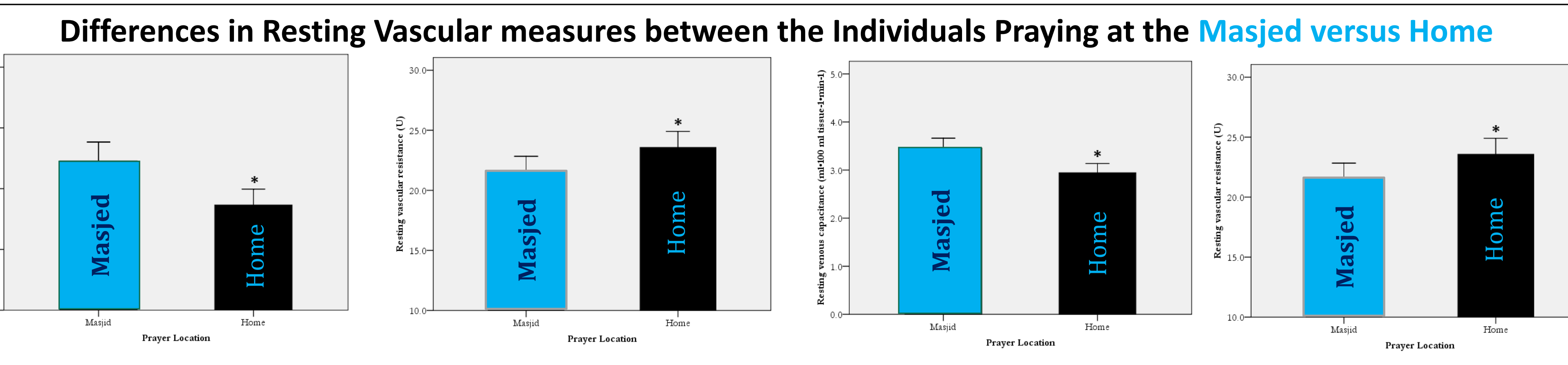

Differences in Post-occlusion Vascular measures between the Individuals Praying at the Masjed versus Home

\section{DISCUSSION}

- The study revealed relationships between vascular function indices and religious-related physical activity, particularly the time and distance required to walk to the Masjed

o These relationships were found in the activities involving large muscle groups (i.e. walking to the Masjed), but not small muscle groups (i.e. standing and bowing).

o Additionally, vascular function was improved in the ones frequently prayed in the Masjid versus the ones prayed at home.

The results confirm the importance of regular PA for health, especially vascular.

- The current findings are unique, as this is the first study to reveal vascular benefits of religious-related physical activities among Muslims, or otherwise.

- Similar to participation in habitual exercise/PA (Alomari, 12), increased blood shear stress during muscle contraction might stimulate these adaptations (Kozakova, 07). o Additionally, exercise/PA can also modify CV risk factors, including hypertension, obesity, and diabetes (Ahmed, 07).

- Therefore, future studies should examine the relationships of religious-related physical activities with other health measures, especially CVD risk factors.

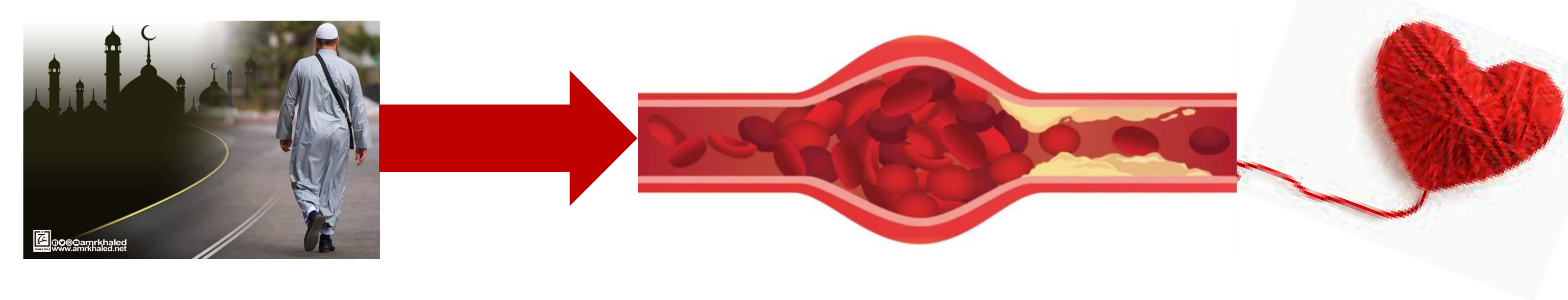

